\title{
Filigrane
}

Écoutes psychanalytiques

\section{Notre ami Samuel}

\section{Louise Grenier}

Volume 27, numéro 1, 2018

URI : https://id.erudit.org/iderudit/1055609ar

DOI : https://doi.org/10.7202/1055609ar

Aller au sommaire du numéro

\section{Éditeur(s)}

Revue Santé mentale au Québec

\section{ISSN}

1192-1412 (imprimé)

1911-4656 (numérique)

Découvrir la revue

Citer ce document

Grenier, L. (2018). Notre ami Samuel. Filigrane, 27(1), 129-130.

https://doi.org/10.7202/1055609ar d'utilisation que vous pouvez consulter en ligne.

https://apropos.erudit.org/fr/usagers/politique-dutilisation/ 


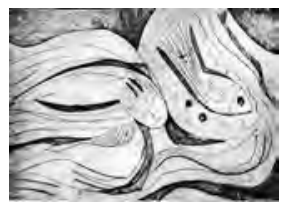

Notre ami Samuel

\section{Louise Grenier}

a plupart du temps, nos rendez-vous avaient lieu au bistro de la librai_rie Olivieri. De loin, je le voyais arriver, hâtant le pas, arborant un large sourire, les yeux pétillants et le geste accueillant. Après un échange rituel de nouvelles, on passait vite au sujet qui nous passionnait tous deux, la psychanalyse.

Nos confidences étaient rares, ou alors elles s'inséraient dans la trame d'une discussion clinique ou théorique. Une façon de réfléchir tout en faisant un détour par notre histoire personnelle. Un jour - cela devait être en 2007 -, je lui avais parlé de mon livre en préparation, Les violences de l'autre. Samuel s'y est tout de suite intéressé. Je m’interrogeais sur les conséquences des maltraitances ou négligences survenues dans un temps qui précède la parole, et l'impossibilité ultérieure d'en faire le récit laissant dans la vie psychique une sorte de "trou» sur lequel bute le rapport à soi et à l'autre. Au-delà de l'événement, il y aurait donc dans pareils cas un silence obligé sur sa propre histoire. Il me semblait que la littérature concentrationnaire, témoignages ou romans, nous aidait à penser les violences de l'autre subies à un âge précoce. C'est à cette occasion que Samuel me raconta son départ forcé de son pays natal, la Bulgarie, pendant la Deuxième Guerre mondiale et ses années à chercher un lieu d'asile, peut-être surtout un lien d'asile ${ }^{1}$, en passant par Israël et la France. Il avait survécu sans trop savoir comment et pourquoi. Au travers de pertes et de séparations familiales, il avait soudainement découvert dans le réel la figure haineuse et destructrice de l'autre. Ce savoir-là, terrible, n'aura cessé de le hanter. Lui qui avait gardé le silence sur ce passé de la Shoah avait entamé l'écriture d'un récit qu'il voulait léguer à ses enfants. Une autre façon de dire l'impossible...

J'avais fait la connaissance de Samuel Pereg à l'UQAM par l'intermédiaire de Mireille Lafortune qui l'aimait beaucoup. Par la suite, je l'avais invité comme conférencier dans mes cours et dans un colloque consacré à un ami commun, Claude Brodeur, décédé récemment. Samuel avait le don de rejoindre émotionnellement son auditoire. Il improvisait, se mettait au diapason de l'autre, parlait de sa conception de la psychanalyse hors institution 
et de bien d'autres choses à partir de son expérience de la cure, la sienne comme celle de ses patients. Raconteur plus que théoricien, sans se mettre au-dessus des autres il paraissait différent. C'est qu'il avait connu l'exil et les ébranlements du monde à un âge précoce; il en parlait rarement, mais c'est dans cette mémoire intime de soi, douloureuse sans doute, qu'il fondait son humanité. Nous n'oublierons pas non plus son sens de l'humour, son originalité et cette joyeuse ironie qui, je crois, le protégeait d'une insupportable proximité et d'une tout aussi insupportable distance.

Louise Grenier louisegrenier.c@gmail.com

\section{Notes}

1. Au départ, lapsus d'écriture, j'avais écrit «un lien d'asile». J'aime cette première formulation qui correspond bien à l'esprit de Samuel. 